\title{
Between, Across, and Beyond Disciplinary Divides: Conceptualizing, Expanding, and Exploring "Childhood"
}

\author{
Rebecca Raby, Shauna Pomerantz, Christine Tardif-Williams, Voula Marinos, Dawn Zinga, and \\ Camille Rousseau, Guest Editors
}

We are excited to present this special issue that emerged out of the Conceptualizing Childhood conference hosted by the Department of Child and Youth Studies at Brock University in October 2017. The conference was aimed at embracing cross- and transdisciplinary engagements with childhood studies. This collection thus includes the work of scholars working across diverse disciplines, including childhood studies, youth studies, digital anthropology, sociology, psychology, theatre studies, girlhood studies, history, kinesiology, communication, and education. The papers are unified in their cross-disciplinary engagements, their attention to children as embedded and interactive, and their navigation, expansion, and exploration of the concept of childhood and its intersections.

The authors of these papers are working across, between, through, and beyond specific disciplines and associated theories, evoking movement toward a transdisciplinarity that aims to create new, innovative thinking. For example, Julian Burton navigates the fruitful intersections of child and youth studies, media studies, subcultural studies, and digital anthropology to ethnographically explore youth agency, coconstruction, and participation in digital spaces with a particular focus on memes. Dawn Zinga, Danielle Sirianni Molnar, Maureen Connolly, and Natalie Tacuri explore girls' competitive dance through examining the rules and guidelines of dance competitions and drawing on interview data with young women involved in competitive dance. Their analysis incorporates self-determination theory, a Foucauldian focus on the production of docile (and resistant) bodies, and Bourdieu's notion of habitus, thus works across disparate theories and their associated disciplinary connections. Ashley Do Nascimento's posthuman reflection on water politics and environmental education considers our collective entanglements with water and water-related weather in the Anthropocene, thus shattering disciplinary and conceptual boundaries of ecology, sociology, and education. Do Nascimento highlights the importance of recognizing the "the intra-activity between the child and the more-than-human environment." Anthony Volk, Richard Mitchell, and Tauhid Khan describe and embrace transdisciplinarity as they advocate for bringing "epistemic humility" and an ethos of civility to the study of adolescent bullying. Both individually and as a collection, these papers showcase the potential to produce new knowledge in child and youth studies by working between, among, and beyond theoretical and disciplinary approaches.

Throughout this special issue there is a focus on how children and youth are embedded and interactive participants in their worlds. The papers explore children's engagement in a range of contexts, including online, in workplaces and educational settings, within research environments, and when engaging in extracurricular activities. Across these contexts, children and youth are actively involved in the relationships around them. Burton sees young people's agency and resistance in the creation of online memes, Zinga et al. consider how young dancers navigate adult regulation, and Volk et al. contend that adolescents must be directly involved in strategies to address teenage bullying. Young people's participation in research has been particularly important to many child and youth studies scholars. Sarah Barriage and Darcey Searles' methodological paper on young children's engagement with video cameras during observational research works across child and youth studies, family studies, and communication studies. They illustrate children's awareness of the camera and its functions, and that children are participants in research as they interact with adults and command attention. Heather Fitzsimmons Frey brings together girlhood studies and theatre history in her innovative performance-based historiographical work to advocate for listening to girls. She enlists $21^{\text {st }}$-century girls to participate in $19^{\text {th }}$-century historical theatre productions and to reflect on their experiences. Her paper offers a glimpse of how girls in the past might have seized opportunities for power 
through participation in at-home theatricals, even if these moments reproduced gender and racialized stereotypes. Together, papers in this issue recognize young people's engagement with the world around them; they also gesture toward the question of how we conceptualize agency and participation in relation to young people.

The final theme unifying these papers is their engagement with the broader concept of childhood and its contested meaning across contexts, ages, and scholarly theorizing. For instance, Zinga and colleagues look at how the governance and regulation of girls involved in competitive dance reflects conceptualizations of childhood, and Fitzsimmons Frey examines the borders between girlhood and womanhood in different time periods. These explorations also necessarily focus on intersections of gender, race, age, and power to highlight the complexity of childhood. Lindsay Sheppard, Rebecca Raby, Wolfgang Lehmann, and Riley Easterbrook reflect on interviews with young people about their first part-time jobs to illustrate how gender intersects with notions of growing up and becoming workers, complicating unitary conceptualizations of childhood, adulthood, and work. Dan Cui's paper draws on interviews with Chinese immigrant students to argue that model minority discourse prevents academics and others from seeing discrimination against Chinese students. Cui expands Bourdieu's notion of habitus to argue that the racialized habitus many Canadians have grown up with fosters discrimination as Chinese students are problematized as overly academic, antisocial, outsiders, and obedient.

As a whole, the papers in this special issue move across methodologies, disciplines, theories, constructions of childhood, and various intersections toward fostering new thinking in current scholarship on childhood. We are thrilled to see these thought-provoking papers assembled, and would like to thank all of our contributors for sharing their work. We also extend a wholehearted thank-you to the reviewers for their thoughtful and thorough feedback. 